\title{
Surface stoichiometry of zinc sulfide and its effect on the adsorption behaviors of xanthate
}

\author{
Meng Wang, Qi Zhang, Wei Hao and Zhong-Xi Sun ${ }^{*}$
}

\begin{abstract}
In this paper, the surface stoichiometry, acid-base properties as well as the adsorption of xanthate at ZnS surfaces were studied by means of potentiometric titration, adsorption and solution speciation modeling. The surface proton binding site was determined by using Gran plot to evaluate the potentiometric titration data. Testing results implied that for stoichiometric surfaces of zinc sulfide, the proton and hydroxide determine the surface charge. For the nonstoichiometric surfaces, the surface charge is controlled by proton, hydroxide, zinc and sulfide ions depending on specific conditions. The xanthate adsorption decreases with increasing solution $\mathrm{pH}$, which indicates an ion exchange reaction at the surfaces. Based on experimental results, the surface protonation, deprotonation, stoichiometry and xanthate adsorption mechanism were discussed.
\end{abstract}

\section{Background}

Zinc sulfide is one of the most important industrial minerals of zinc metal, which is usually recovered by flotation technology, in which the mineral surfaces are treated hydrophobic. Synthetic zinc sulfide is also well known as electroluminescence material. In fact, due to its wide applications and potential use as a spintronic material in high technology field, it was one of the most studied luminescence [1-10], photo catalyst [11], special morphology [11-16] and mesoporous materials [17-21] in inorganic synthesis. It was reported that transition metal doped nanocrystals of semiconductor like zinc sulfide can yield both high luminescence efficiencies and life time shortening [1]. The doped semiconductor nanocrystals seem to represent a new class of luminescent material, with wide range application in e.g. display, lighting and lasers [2-10]. In past years the dramatic surface effect of nano sized $\mathrm{ZnS}$ was reported [22], which states that when the surface of a $\mathrm{ZnS}$ nanoparticle gets wet, its entire crystal structure rearranges to become more ordered, closer to the structure of a bulk piece of solid ZnS. It was also reported [23] that zinc sulfide nanoparticles, a mere 10 atoms across have a disordered crystal structure that puts them under constant strain, increasing the stiffness of the particles. Obviously surface chemical property of zinc sulfide plays a critical

\footnotetext{
* Correspondence: sunzx@ujn.edu.cn

School of Chemistry and Chemical Engineering, University of Jinan, Jinan 250022, China
}

role in these phenomena. When zinc sulfide are put into aqueous solution, the surface hydration takes place at once, the adsorption of proton and hydroxide ions make the surface either positively or negatively charged in the absence of foreign ions. Due to the sensitivity of sulfide ions to oxygen, redox reactions at the surfaces may take place as well. The surface properties are influenced by overall equilibrium of surface and solution chemical reactions including solution acid base and redox reactions, surface complexations, precipitation and dissolution. All theses reactions are very fundamental to understanding of aforementioned mineral flotation, surface modification and inorganic material synthesis processes. Therefore, it is meaningful to study the acid-base and reduction properties of zinc sulfide as well as their correlation with these processes. Furthermore, the surface stoichiometry of zinc sulfide will not only influence the surface charge but also have some impact on the preparation of luminance material, inorganic synthesis of nanoparticles, which deserve a deep going study.

The surface complexation of zinc sulfide in relation to mineral flotation was studied [24-27] and some surface reaction constants were reported. Xanthate having the structure $\mathrm{ROC}(=\mathrm{S}) \mathrm{S}^{-} \mathrm{M}^{+}\left(\mathrm{R}=\right.$ alkyl; $\left.\mathrm{M}^{+}=\mathrm{Na}^{+}, \mathrm{K}^{+}\right)$is a type of collector widely used in sulfide mineral floatation. The uses of xanthate as capping agents for stabilizing colloids $[28,29]$ and as precursors for metal sulfide nano-particles [30-33] have also been studied and the adsorption mechanism plays an important role in theses 
process and deserves further studies. Although the surface stoichiometry of zinc sulfide may profoundly affect its adsorption properties, the systematic knowledge on this aspect is lacking.

In this paper, surface stoichoimetry, acid-base and redox properties as well as the adsorption of xanthate at $\mathrm{ZnS}$ surfaces were studied by means of potentiometric titration, adsorption and solution speciation modeling. Testing results indicate that the state of surface stoichiometry of $\mathrm{ZnS}$ plays an important role in its adsorption process. The adsorption of xanthate and the surface charge at the $\mathrm{ZnS}$ surfaces is in the order of zinc rich $\mathrm{ZnS}>$ stoichiometric $\mathrm{ZnS}>$ sulfur rich $\mathrm{ZnS}$.

\section{Results and Discussions}

\section{Chemical reactions in $\mathrm{ZnS}-\mathrm{H}_{2} \mathrm{O}$ system}

There are four types of chemical reactions in $\mathrm{ZnS}-\mathrm{H}_{2} \mathrm{O}$ system, i.e. solution acid-base reaction, solution redox reaction, precipitation and dissolution as well as surface complexation reaction [34]. In certain $\mathrm{pH}$ and redox conditions, some chemical reactions play more important roles than others and consequently the relevant reaction products become major species in the system. Relevant chemical reactions and their equilibrium constants collected from published papers and relevant database [24-27,35], are listed in Table 1.

The overall chemical equilibriums of these reactions decide which reaction is more important than others at each specific condition, such as $\mathrm{pH}$, concentration etc., and sometimes several reactions play important roles simultaneously. Based on these chemical reactions excluding surface complexation, an $\mathrm{E}_{\mathrm{h}}-\mathrm{pH}$ diagram can be established and shows in Figure 1. From Figure 1, the predominant area of various species at varying $E_{h}$ and $p H$ value can be seen. Here, $E_{h}$ defined as the potential of standard hydrogen electrode represents the redox level, when $E_{h}$ is negative indicating a reductive atmosphere, and vice versa. It is obvious that $\mathrm{ZnS}$ is stable in acidic $\mathrm{pH}$ when $\mathrm{E}_{\mathrm{h}}$ is below zero. At alkaline $\mathrm{pH}$, however, $\mathrm{ZnS}$ is stable at more negative $E_{h}$ value. The oxidation product of $\mathrm{ZnS}$ is zinc sulfate in acidic solution and zinc hydroxide precipitate in alkaline solution. Between $\mathrm{pH}$ about 7 to 10 , at more positive $\mathrm{E}_{\mathrm{h}}$, the dominant species is $\mathrm{Zn}_{4}(\mathrm{OH})_{6} \mathrm{SO}_{4}(\mathrm{~s})$. When $E_{h}$ is between $-0.9 \mathrm{~V}$ and $-0.4 \mathrm{~V}$, the $\mathrm{ZnS}$ is dominant species. In order to compare the influence of excess zinc or sulfide ions to the system, the distribution diagrams in three different cases, i.e. the equal amount of zinc and sulfide ions, zinc in excess and sulfide in excess is presented in Figure $2 \mathrm{a}, \mathrm{b}$ and $2 \mathrm{c}$ respectively. It can be seen from Figure $2 \mathrm{a}$ that when zinc and sulfide ions are in equal concentration (100 $\mathrm{mM})$, the solid $\mathrm{ZnS}(\mathrm{s})$ is dominating species in entire $\mathrm{pH}$ range between 3 and 11, free zinc ion only appears
Table 1 Chemical reaction in $\mathrm{Zn}^{2}{ }^{+}-\mathrm{HS}^{-}-e^{-}-\mathrm{H}_{2} \mathrm{O}$ system

\begin{tabular}{|c|c|c|}
\hline (1) Acid-base reactions & $\log K$ & No. \\
\hline $\mathrm{H}^{+}+\mathrm{HS}^{-}<=>\mathrm{H}_{2} \mathrm{~S}$ & 6.99 & $\overline{(1)}$ \\
\hline $\mathrm{H}^{+}+\mathrm{HS}^{-} \Leftrightarrow=\mathrm{H}_{2} \mathrm{~S}(\mathrm{~g})$ & 7.99 & (2) \\
\hline $\mathrm{HS}^{-}<=>\mathrm{H}^{+}+\mathrm{S}^{2-}$ & -19.0 & (3) \\
\hline $\mathrm{H}_{2} \mathrm{O} \Leftrightarrow=>\mathrm{H}^{+}+\mathrm{OH}^{-}$ & -14.00 & (4) \\
\hline $\mathrm{Zn}^{2+}+2 \mathrm{HS}^{-} \Leftrightarrow \mathrm{Zn}(\mathrm{HS})_{2}$ & 12.82 & (5) \\
\hline $\mathrm{Zn}^{2+}+3 \mathrm{HS}^{-} \Leftrightarrow=\mathrm{Zn}(\mathrm{HS})_{3}^{-}$ & 16.1 & (6) \\
\hline $\mathrm{Zn}^{2+}+4 \mathrm{HS}^{-}<=>\mathrm{Zn}(\mathrm{HS})_{4}^{2-}$ & 14.64 & (7) \\
\hline $\mathrm{Zn}^{2+}+2 \mathrm{H}_{2} \mathrm{O} \Leftrightarrow=2 \mathrm{H}^{+}+\mathrm{Zn}(\mathrm{OH})_{2}$ & -16.4 & (8) \\
\hline $\mathrm{Zn}^{2+}+3 \mathrm{H}_{2} \mathrm{O} \Leftrightarrow 3 \mathrm{H}^{+}+\mathrm{Zn}(\mathrm{OH})_{3}^{-}$ & -28.2 & (9) \\
\hline $\mathrm{Zn}^{2+}+4 \mathrm{H}_{2} \mathrm{O} \Leftrightarrow=>\mathrm{H}^{+}+\mathrm{Zn}(\mathrm{OH})_{4}^{-}$ & -41.3 & $(10)$ \\
\hline $2 \mathrm{Zn}^{2+}+6 \mathrm{H}_{2} \mathrm{O} \Leftrightarrow=>6 \mathrm{H}^{+}+\mathrm{Zn}_{2}(\mathrm{OH})_{6}^{2-}$ & -54.3 & (11) \\
\hline $2 \mathrm{Zn}^{2+}+\mathrm{H}_{2} \mathrm{O} \Leftrightarrow=>\mathrm{H}^{+}+\mathrm{Zn}_{2} \mathrm{OH}^{3+}$ & -9.0 & (12) \\
\hline $4 \mathrm{Zn}^{2+}+4 \mathrm{H}_{2} \mathrm{O} \Leftrightarrow=>4 \mathrm{H}^{+}+\mathrm{Zn}_{4}(\mathrm{OH})_{4}^{4+}$ & -27.0 & (13) \\
\hline $\mathrm{Zn}^{2+}+\mathrm{H}_{2} \mathrm{O} \Leftrightarrow>\mathrm{H}^{+}+\mathrm{ZnOH}^{+}$ & -7.5 & (14) \\
\hline $\mathrm{Zn}^{2+}+2 \mathrm{HS}^{-}<=>\mathrm{H}^{+}+\mathrm{ZnS}(\mathrm{HS})^{-}$ & 6.84 & (15) \\
\hline $\mathrm{Zn}^{2+}+3 \mathrm{HS}^{-} \Leftrightarrow=>\mathrm{H}^{+}+\mathrm{ZnS}(\mathrm{HS})_{2}{ }^{2-}$ & 6.15 & (16) \\
\hline
\end{tabular}

\section{(2)Redox reactions}

$2 \mathrm{H}^{+}+2 \mathrm{e}^{-}<=>\mathrm{H}_{2}$

$-3.15 \quad(17)$

$2 \mathrm{H}^{+}+2 \mathrm{e}^{-}<=>\mathrm{H}_{2}(\mathrm{~g})$

$0.0 \quad(18)$

$2 \mathrm{H}_{2} \mathrm{O} \Leftrightarrow 2 \mathrm{H}^{+}+2 \mathrm{e}^{-}+\mathrm{H}_{2} \mathrm{O}_{2}$

$-59.60(19)$

$4 \mathrm{HS}^{-} \Leftrightarrow 2 \mathrm{H}^{+}+6 \mathrm{e}^{-}+\mathrm{H}_{2} \mathrm{~S}_{4}$

$7.88 \quad(20)$

$5 \mathrm{HS}^{-} \Leftrightarrow>3 \mathrm{H}^{+}+8 \mathrm{e}^{-}+\mathrm{H}_{2} \mathrm{~S}_{5}$

$8.99 \quad(21)$

$4 \mathrm{HS}^{-}<=3 \mathrm{H}^{+}+6 \mathrm{e}^{-}+\mathrm{HS}_{4}$

$3.68 \quad(22)$

$5 \mathrm{HS}^{-} \Leftrightarrow 4 \mathrm{H}^{+}+8 \mathrm{e}^{-}+\mathrm{HS}_{5}$

$5.09 \quad(23)$

$2 \mathrm{H}_{2} \mathrm{O} \Leftrightarrow 4 \mathrm{H}^{+}+4 \mathrm{e}^{-}+\mathrm{O}_{2}$

-86.08 (24)

$2 \mathrm{H}_{2} \mathrm{O} \Leftrightarrow=>4 \mathrm{H}^{+}+4 \mathrm{e}^{-}+\mathrm{O}_{2}(\mathrm{~g})$

$-83.12(25)$

$3 \mathrm{H}_{2} \mathrm{O} \Leftrightarrow=>6 \mathrm{H}^{+}+6 \mathrm{e}^{-}+\mathrm{O}_{3}$

-156.05 (26)

$-153.25(27)$

$-5.09 \quad(28)$

$-12.73 \quad(29)$

$-28.79 \quad(30)$

$-7.27 \quad(31)$

$-3.022 \quad(32)$

$-1.007 \quad$ (33)

$0.84 \quad(34)$

$-37.09 \quad(35)$

-33.69 (36)

$-26.52 \quad(37)$

$-33.70 \quad(38)$

$-71.25 \quad(39)$

$-27.11(40)$

$-29.87 \quad(41)$

$-31.71 \quad(42)$

$-75.43(43)$

-133.65 (44)

$-54.88(45)$

$-28.03 \quad(46)$

$-28.35 \quad(47)$

$-64.10(48)$

$-133.07(49)$

$-26.49(50)$ 
Table 1 Chemical reaction in $\mathrm{Zn}^{2}{ }^{+}-\mathrm{HS}^{-}-\mathrm{e}^{-}-\mathrm{H}_{2} \mathrm{O}$ system (Continued)

\begin{tabular}{|c|c|c|}
\hline $\mathrm{Zn}^{2+}+4 \mathrm{H}_{2} \mathrm{O}+\mathrm{HS}^{-}<=>9 \mathrm{H}^{+}+8 \mathrm{e}^{-}+\mathrm{ZnSO}_{4}$ & -31.32 & $(51)$ \\
\hline \multicolumn{3}{|l|}{ 3) Precipitation and dissolution reactions } \\
\hline$\overline{\mathrm{Zn}^{2+}+2 \mathrm{H}_{2} \mathrm{O}<=>2 \mathrm{H}^{+}+\mathrm{Zn}(\mathrm{OH})_{2}(\mathrm{~s})}$ & -12.45 & (52) \\
\hline $\mathrm{HS}^{-}<=\mathrm{H}^{+}+2 \mathrm{e}^{-}+\mathrm{S}(\mathrm{s})$ & 2.15 & $(53)$ \\
\hline $2 \mathrm{e}^{-}+\mathrm{Zn}^{2+}=\mathrm{Zn}(\mathrm{c})$ & -25.76 & (54) \\
\hline $\mathrm{Zn}^{2+}+\mathrm{HS}^{-}<=>\mathrm{H}^{+}+\mathrm{ZnS}(\mathrm{s})$ & 9.06 & $(55)$ \\
\hline $2 \mathrm{Zn}^{2+}+6 \mathrm{H}_{2} \mathrm{O}+\mathrm{HS}^{-} \Leftrightarrow=>11 \mathrm{H}^{+}+8 \mathrm{e}^{-}+\mathrm{Zn}_{2}(\mathrm{OH})_{2} \mathrm{SO}_{4}(\mathrm{~s})$ & -41.19 & $(56)$ \\
\hline $\begin{array}{l}3 \mathrm{Zn}^{2+}+9 \mathrm{H}_{2} \mathrm{O}+2 \mathrm{HS}^{-}<=>20 \mathrm{H}^{+}+16 \mathrm{e}^{-}+\mathrm{Zn}_{3} \mathrm{O}\left(\mathrm{SO}_{4}\right)_{2} \\
\text { (s) }\end{array}$ & -86.40 & (57) \\
\hline $4 \mathrm{Zn}^{2+}+10 \mathrm{H}_{2} \mathrm{O}+\mathrm{HS}^{-} \Leftrightarrow>15 \mathrm{H}^{+}+8 \mathrm{e}^{-}+\mathrm{Zn}_{4}(\mathrm{OH})_{6} \mathrm{SO}_{4}(\mathrm{~s})$ & -62.09 & $(58)$ \\
\hline $\mathrm{Zn}^{2+}+4 \mathrm{H}_{2} \mathrm{O}+\mathrm{HS}^{-} \Leftrightarrow=>9 \mathrm{H}^{+}+8 \mathrm{e}^{-}+\mathrm{ZnSO}_{4}(\mathrm{~s})$ & -36.70 & $(59)$ \\
\hline $\mathrm{Zn}^{2+}+\mathrm{HS}^{-}<=9 \mathrm{H}^{+}+8 \mathrm{e}^{-}+\mathrm{ZnSO}_{4} \cdot 6 \mathrm{H}_{2} \mathrm{O}(\mathrm{s})$ & -31.93 & $(60)$ \\
\hline $\mathrm{Zn}^{2+}+\mathrm{HS}^{-}<=>9 \mathrm{H}^{+}+8 \mathrm{e}^{-}+\mathrm{ZnSO}_{4} \cdot 7 \mathrm{H}_{2} \mathrm{O}(\mathrm{s})$ & -31.73 & $(61)$ \\
\hline \multicolumn{3}{|l|}{ (4) Surface complexation reactions* } \\
\hline$\overline{\equiv \mathrm{Sn}}+\mathrm{H}^{+}<=>\equiv \mathrm{ZnSH}^{+}$ & 6.91 & $(62)$ \\
\hline$\equiv \mathrm{SZn}+\mathrm{H}_{2} \mathrm{O}<=>\equiv \mathrm{SnOH}^{-}+\mathrm{H}^{+}$ & -10.28 & $(63)$ \\
\hline$\equiv \mathrm{SZn}+2 \mathrm{H}^{+}<=>\equiv \mathrm{SH}_{2}+\mathrm{Zn}^{2+}$ & 9.59 & $(64)$ \\
\hline
\end{tabular}

* Surface complexationwas a concept presented by Stumm and Schindler et al in the end of 1960s and the beginning of 1970s and now it is widely used as a useful tool to treat the sorption data in mineral suspensions [34]. The basic ideal of that is to regard the mineral surfaces as a functional groups carrier; therefore the surface chemical reaction can be treated in the same way as those of solution chemical reactions. The only difference between the surface and solution chemical reactions is the former one has surface charge, thus the situation of the electrical double layer EDL of mineral surfaces should be considered in performing the surface complexation studies.

The three surface complexation reactions of $\mathrm{ZnS}$ presented in table 1 are the surface protonation (62), deprotonnation (63) and ion exchange (64) reaction respectively. $\equiv \mathrm{SZn}$ denotes the surface binding site of $\mathrm{ZnS}$.

at $\mathrm{pH}$ below 4 and in very low level $(<0.1 \%)$, the dissolution is negligible. When zinc ions are in $1 \%$ excess, i.e. in the presence of $101 \mathrm{mM} \mathrm{Zn}^{2+}$ and $100 \mathrm{mM} \mathrm{HS}^{-}$, we can see from Figure $2 b$ that besides the formation

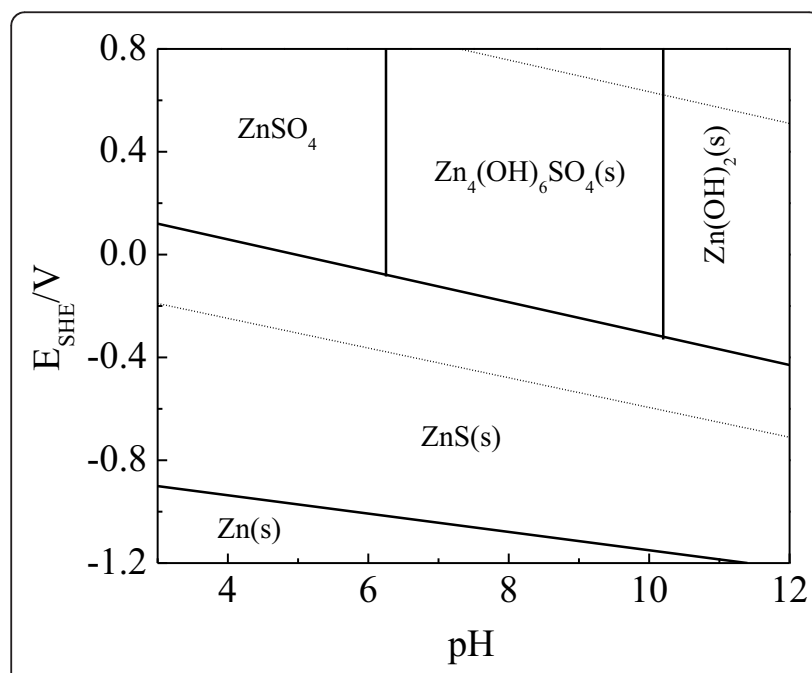

Figure 1 Predominant area diagram in $\mathrm{Zn}^{2+}-\mathrm{HS}^{-}-\mathrm{e}^{-}-\mathrm{H}_{2} \mathrm{O}$ system $\left(\mathrm{Zn}^{2+}=0.1 \mathrm{M} ; \mathrm{HS}^{-}=0.1 \mathrm{M}\right)$. of $\mathrm{ZnS}(\mathrm{s})$, among the soluble zinc species, $\mathrm{Zn}^{2+}, \mathrm{ZnOH}$ ${ }^{+}, \mathrm{Zn}(\mathrm{OH})_{2}$, is in turn dominating with increasing solution $\mathrm{pH}$. When solution $\mathrm{pH}$ is higher than $8.2, \mathrm{Zn}(\mathrm{OH})$ ${ }_{2}$ (s) starts to form and becomes main species only after $\mathrm{ZnS}(\mathrm{s})$ in higher $\mathrm{pH}$. When $\mathrm{pH}$ is approaching $11, \mathrm{Zn}$ $(\mathrm{OH})_{3}{ }^{-}$appears. However, when hydrogen sulfide ions are in $1 \%$ excess, i.e. in the presence of $101 \mathrm{mM} \mathrm{HS}^{-}$

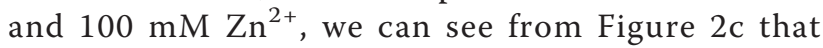
besides the formation of $\mathrm{ZnS}(\mathrm{s})$, in the soluble zinc species, $\mathrm{H}_{2} \mathrm{~S}, \mathrm{HS}^{-}$is in turn dominating with increasing solution $\mathrm{pH}$. The adsorption of these solution species at the surface of zinc sulfide may affect its surface charge. In the presence of oxygen the surface and solution species distribution will be changed due to the oxidation of zinc sulfide. However, in some technological processes the oxidation of fresh surface may be a slow process, the aforementioned distribution diagram may still be largely applicable depending on the situation of surface oxidation.

\section{Surface acidity}

Some typical potentiometric titration results of stoichiometric zinc sulfide are presented in Figure $3 . \mathrm{H}_{\mathrm{t}}$ is defined as total acid concentration i.e.

$$
\mathrm{H}_{\mathrm{t}}=\left(\mathrm{H}_{\mathrm{a}} * \mathrm{~V}_{\mathrm{a}}-\mathrm{H}_{\mathrm{b}} * \mathrm{~V}_{\mathrm{b}}\right) /\left(\mathrm{V}_{0}+\mathrm{V}_{\mathrm{a}}+\mathrm{V}_{\mathrm{b}}\right)
$$

Here, $H_{a}, V_{a}, H_{b}, V_{b}$, and $V_{0}$ denote the acid concentration of burette, added acid volume, base concentration of burette, added base volume and original volume respectively.

It can be seen that between $\mathrm{pH} 4$ to 10 the solution of $0.1 \mathrm{M} \mathrm{NaNO}_{3}$ has no buffer capacity. When the concentration of $\mathrm{ZnS}$ sample suspension is $0.5 \mathrm{~g} / \mathrm{L}$, the $\mathrm{pH}$ buffer range is between $\mathrm{pH} 7$ to 9 and the buffer capacity and range are getting bigger and widen when the solid concentration is increased. With increasing the solid concentration from 0 to $2 \mathrm{~g} / \mathrm{L}$, the increase of $\mathrm{pH}$ buffer capacity of sample suspension indicates clearly the influence of the concentration of surface binding site and the acid-base properties of these sites. As well known that the solubility of zinc sulfide is very limited, the $\mathrm{pH}$ buffer from the soluble zinc ions should be negligible therefore the $\mathrm{pH}$ buffer of solution can only originate from the surfaces. If so, the change of solid concentration will correspondingly change the buffer capacity and it is indeed the case. We have qualitatively checked the soluble species in the supernatant of $\mathrm{ZnS}$ suspension by titrating with acid solution and found out that there is no $\mathrm{pH}$ buffer capacity, which means the soluble ions is negligible. From Figure 3 it can be seen clearly that the $\mathrm{pH}$ change behaviors of zinc sulfide suspension with changing total concentration of acid varies as a function of solid concentration. The higher the solid 

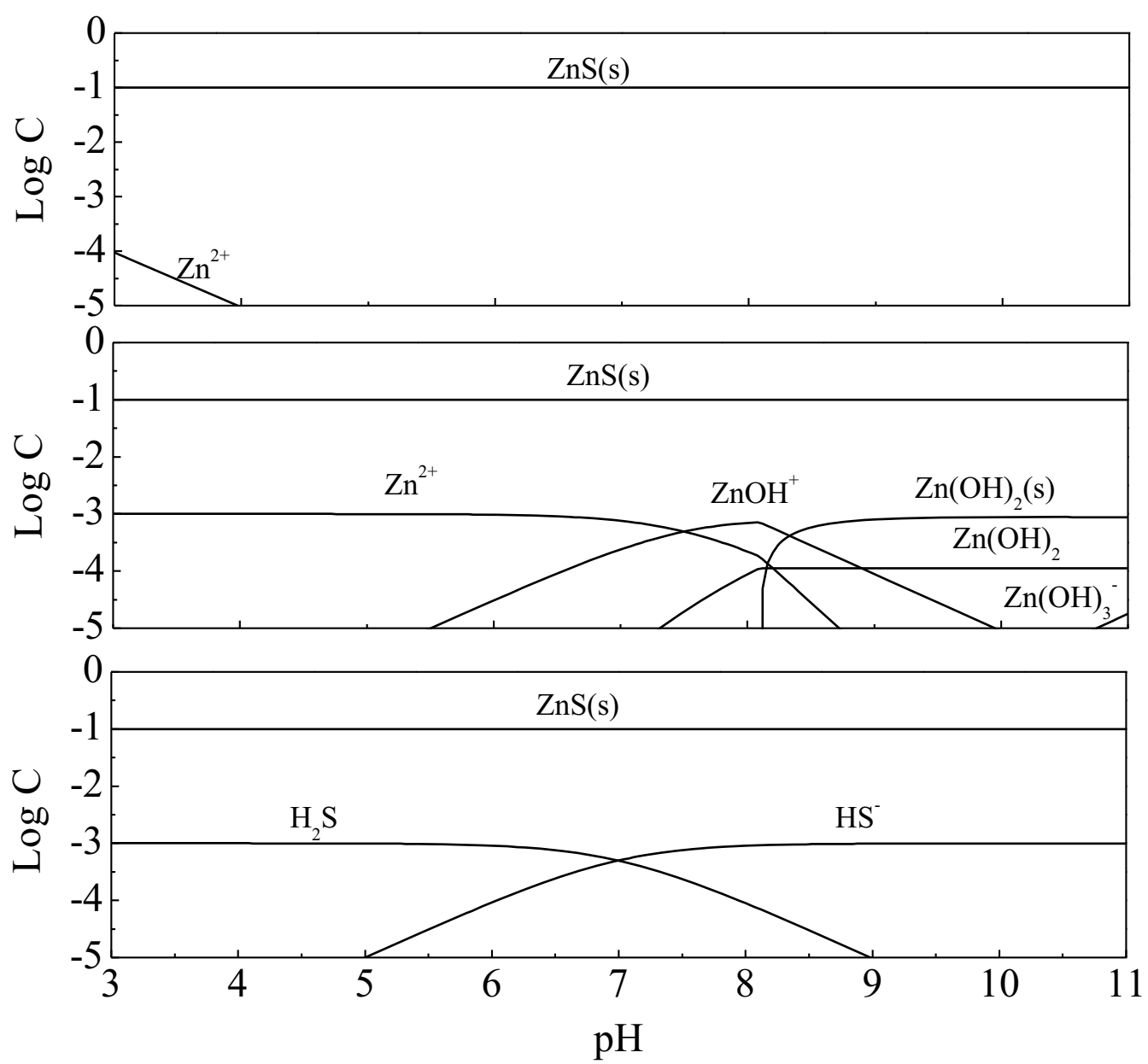

Figure 2 Distribution of zinc species in $\mathrm{Zn}^{2+}-\mathrm{HS}^{-}-\mathrm{H}_{2} \mathrm{O}$ system as a function of $\mathrm{pH}$ in the presence of: a) $100 \mathrm{mM} \mathrm{Zn}^{2+}, 100 \mathrm{mM} \mathrm{HS}$; b)

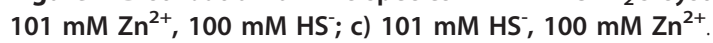

concentration of zinc sulfide is the more the $\mathrm{pH}$ buffer capacity of corresponding suspension.

In the suspension of zinc sulfide samples prepared in zinc rich or sulfide rich solution, the $\mathrm{pH}$ changes as a function of total acid concentration are shown in Figure 4. Figure 4 indicates that the stoichiometric zinc sulfide surface has quite different acid base properties from that of either zinc excess or sulfide excess surface. The state of surface stoichiometry plays an important role for its surface chemical properties. For the zinc rich samples, the $\mathrm{pH}$ buffer capacity and range are increased, which suggests that the $\mathrm{pH}$ buffer capacity in this case comes from surface binding sites. For the sulfide rich sample, although some changes can be observed in $\mathrm{pH}$ buffer capacity and range, but they are marginal in comparison with stoichiometric and zinc rich sample. Between $\mathrm{pH} 6$ and 9.5 some $\mathrm{pH}$ buffer behaviors can be observed, indicating deprotonation at surface binding sites. These phenomena indicate that these samples have quite different surface acidity constants. If we compare the titration curves of sulfide rich samples with that of pure $0.1 \mathrm{M}$ $\mathrm{NaNO}_{3}$ medium, the differences is obvious. In fact no $\mathrm{pH}$ buffer behavior can be observed for the $0.1 \mathrm{M}$ $\mathrm{NaNO}_{3}$ solution (see Figure 3). It seems that the adsorption of sulfide ions at surface zinc site reduce the $\mathrm{pH}$ buffer capacity brought by surface zinc site hydrolysis and the surface stoichiometry affects the surface acidity constant of $\mathrm{ZnS}$ samples.

\section{Surface stoichiometry}

The surface state of zinc sulfide can be schematically depicted in Figure 5, black and white circle represent zinc ion and sulfide ion respectively. Here number 1, 2, 3 respectively demonstrates stoichiometric, zinc rich and sulfide rich zinc sulfide surface before hydration and number 4, 5, 6 respectively shows stoichiometric, zinc rich and sulfide rich zinc sulfide surface after hydration. In water solution, the stoichiometric surface of zinc sulfide should have equal amount of zinc and sulfide ions and be neutrally charged at the point of zero charge i.e. $\mathrm{pH}_{\mathrm{pzc}}$. The 


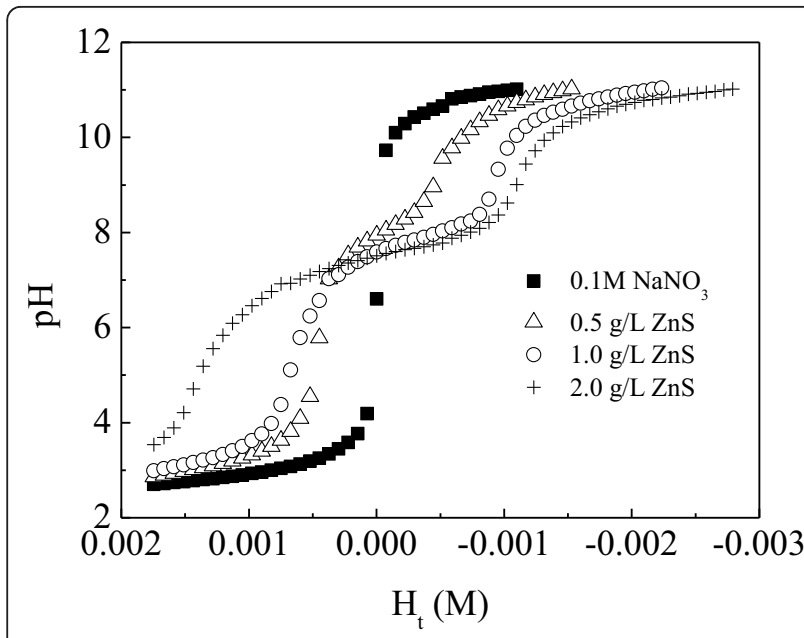

Figure $3 \mathrm{pH}$ changes of zinc sulfide suspension with varying solid concentration as a function of total acid concentration $\mathrm{H}_{\mathbf{t}}$.

zinc rich or the sulfide rich surface should be either positively or negatively charged. These surfaces tend to adsorb water, hydroxide or proton to reduce the surface energy. Consequently proton and hydroxide are balanced or one of them dominating at the surfaces. Some notable phenomena can be shown in Figure 6a and 6b when sulfide solution is titrated with zinc ions or vice versa.

It can be seen from Figure 6 that when $20 \mathrm{~mL} 0.1 \mathrm{M}$ sulfide solution is titrated with $0.1 \mathrm{M}$ zinc ion solution, the equivalent volume of zinc ion solution should be about $20 \mathrm{~mL}$ and is indeed $20 \mathrm{~mL}$. However, when the $20 \mathrm{~mL} 0.1 \mathrm{M}$ zinc ion solution is titrated with $0.1 \mathrm{M}$ sulfide solution the equivalent volume of sulfide is about $19 \mathrm{~mL}$. This phenomenon may be expressed as that when zinc ion solution is titrated with sulfide ion solution, the equivalent volume corresponds to the surface

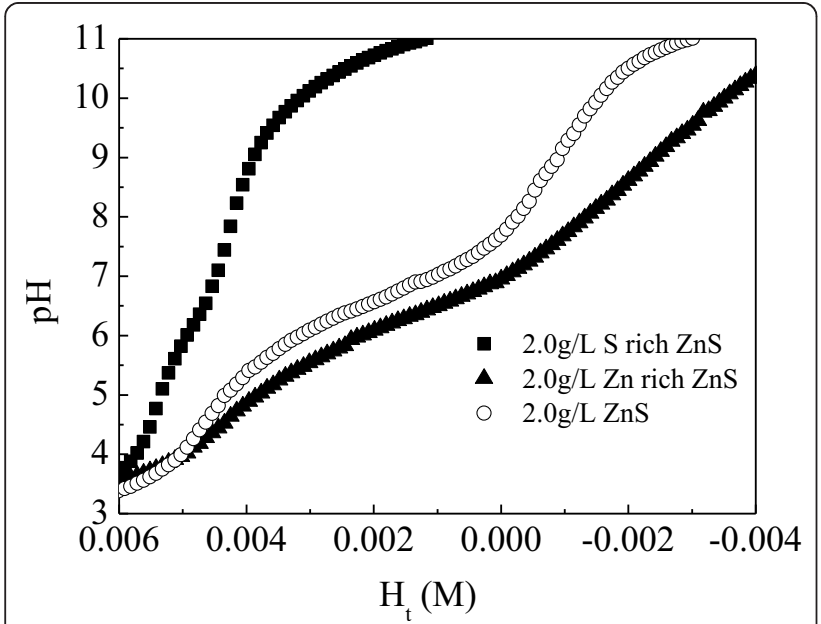

Figure $4 \mathrm{pH}$ changes in sulfide rich, zinc rich and stoichiometric zinc sulfide suspension as a function of $H_{t}$

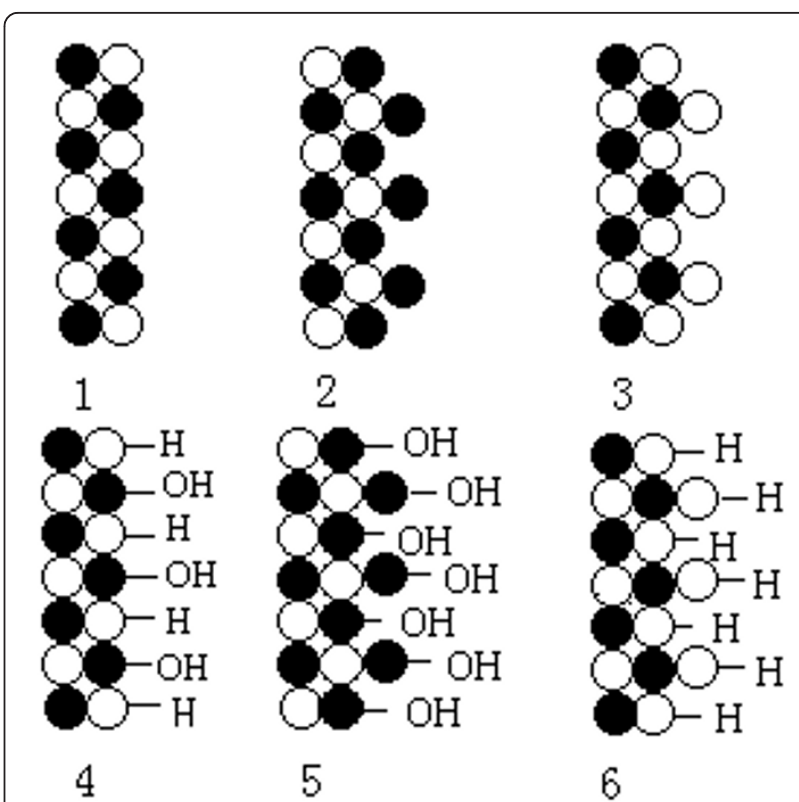

Figure 5 Schematic illustration of the surface stoichiometry and hydration of zinc sulfide 1 . Non hydrated stoichiometric ZnS surface; 2. Non hydrated zinc rich ZnS surface; 3. Non hydrated sulfur rich ZnS surface; 4 . hydrated stoichiometric ZnS surface, 5. hydrated zinc rich ZnS surface; 6 . hydrated sulfur rich ZnS surface.

state of 5 in Figure 5. After the excess zinc ions in solution is consumed by forming bulk zinc sulfide and zinc rich zinc sulfide surfaces, the addition of sulfide ions induces the quick increase of hydroxide in solution and sudden jump of the $\mathrm{pH}$ value.

\section{Determination of surface proton binding site}

The surface proton binding site can be determined by acid-base titration method. The way to do it is using Gran plot [36] to evaluate the titration data. A certain amount of acid is adding to the zinc sulfide suspension, and the excess acid is titrated with hydroxide. Due to the protonation of the zinc sulfide surfaces, the excess of acid in the suspension is reduced with increasing solid concentration. The solubility product of $\mathrm{ZnS}$ is $\sim 10^{-24}$, thus the quantity of soluble species is considered to be negligible, the proton binding site is determined in this way. From the Gran function of the zinc sulfide suspension (see Figure 7), the equivalence point (Ve) of acid-base titration is decreased from $2.25 \mathrm{~mL}$ to $0.3 \mathrm{~mL}$ with increasing solid concentration" The proton binding site of the solid surface in the suspension is defined as

$$
\mathrm{H}_{\mathrm{s}}=\mathrm{H}_{\mathrm{ad}}-\mathrm{H}_{\mathrm{ex}}
$$

Here $\mathrm{H}_{\mathrm{s}}, \mathrm{H}_{\mathrm{ad}}$ and $\mathrm{H}_{\mathrm{ex}}$ denote surface proton binding site, total added proton and excess proton respectively. The $\mathrm{H}_{\mathrm{ex}}$ can be determined by Ve of acid-base titration. 

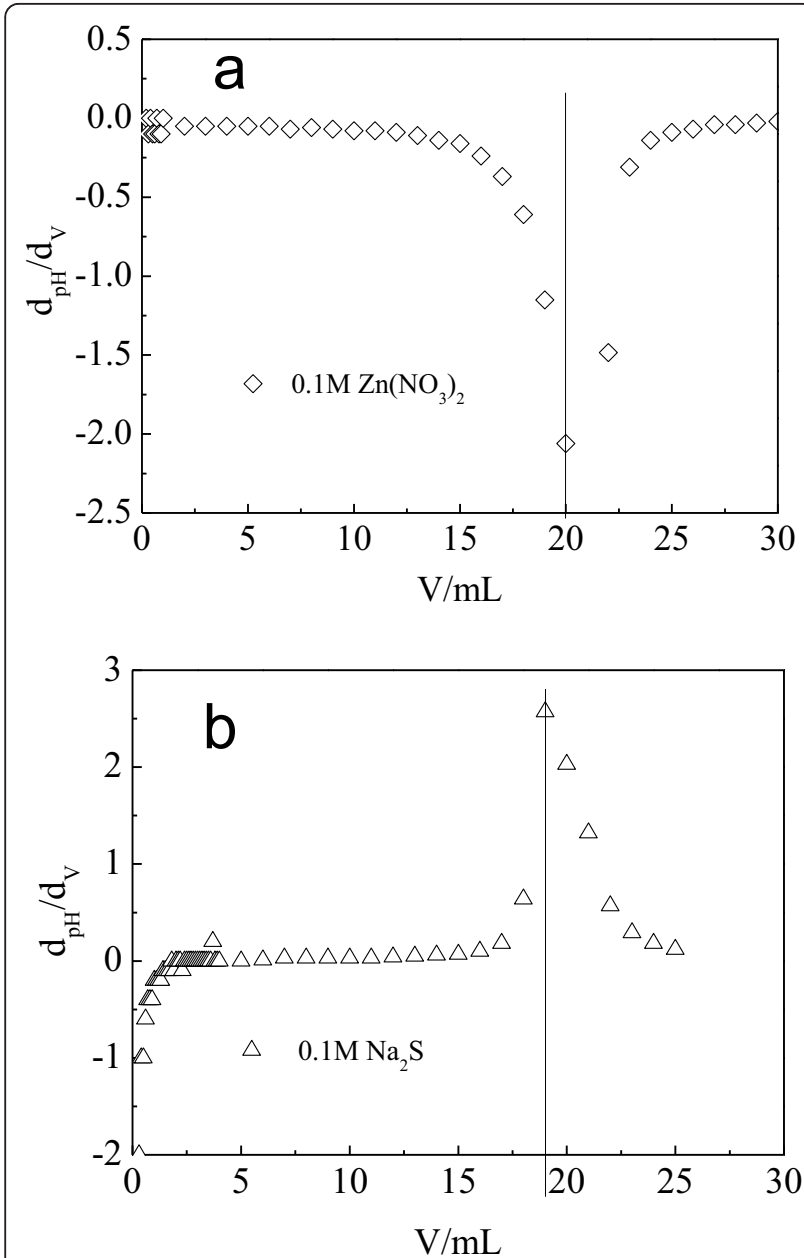

Figure 6 Derivation of $\mathrm{pH}(\mathrm{dpH} / \mathrm{dv})$ as a function of sulfide or zinc ions addition during zinc sulfide formation. a. $0.1 \mathrm{M}$ sodium sulfide solution is titrated with $0.1 \mathrm{M}$ zinc nitrate solution. b. $0.1 \mathrm{M}$ zinc nitrate solution is titrated with $0.1 \mathrm{M}$ sodium sulfide solution.

The proton binding site of zinc sulfide surfaces in the suspension as a function of solid concentration, which is largely linearly related, is shown in Figure 8, bearing in mind that some errors can occur in the process of acid base titration due to mineral coagulation or flocculation.

\section{Xanthate adsorption}

In sulfide mineral flotation process, the ethyl xanthate can only be weakly adsorbed at the surface of zinc sulfide. The longer carbon chain in xanthate, the better the adsorption at the surface of zinc sulfide is. However, no matter which xanthate is used, the functional group and the adsorption mechanism are basically the same. Zinc sulfide has advantage of being IR transparence material and the adsorbents at the surfaces can be easily detected by FTIR techniques. The IR spectra of various zinc sulfide sample after adsorption of octyl xanthate are

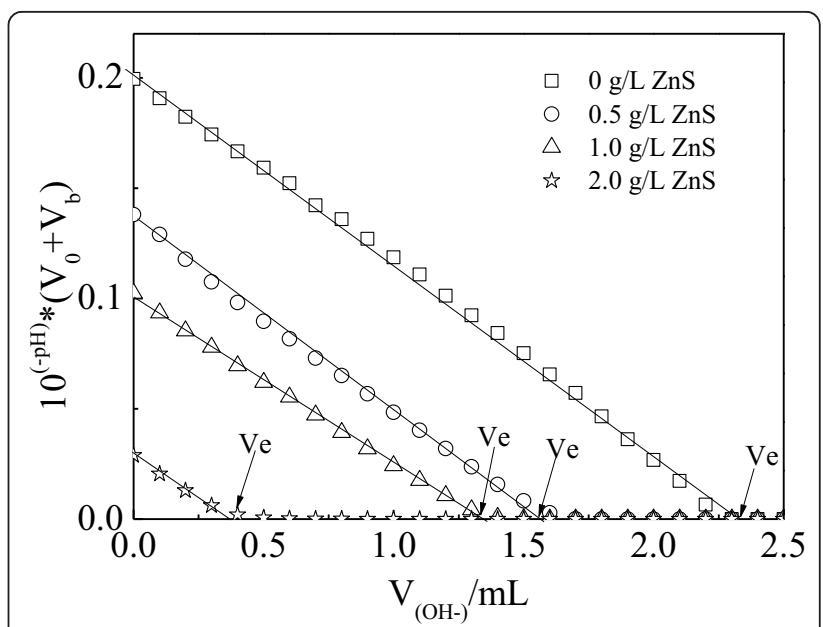

Figure 7 Gran plots of zinc sulfide suspensions.

presented in Figure 9. In Figure 9, the fingerprint region of adsorbed octyl xanthate (OX) is shown. As literature reported [37,38], the bands in the region of 1200-1030 $\mathrm{cm}^{-1}$ are mainly influenced by the $\mathrm{CS}_{2}$ symmetric $\left(v_{\mathrm{s}}\right)$ and asymmetric $\left(v_{\mathrm{as}}\right)$ vibrations, and by the $\mathrm{COC}$ asymmetric $\left(v_{\text {as }}\right)$ stretch with some influence from $\mathrm{CS}_{2} / \mathrm{COC}$ deformation $(\delta)$ vibrations as well as rocking $\left(v_{\mathrm{r}}\right)$, wagging $\left(v_{\mathrm{w}}\right)$ and twisting $\left(v_{\mathrm{t}}\right)$ of $\mathrm{CH}_{2} / \mathrm{CH}_{3}$ entities in the alkyl chain. Similar peak assignments have also been found in reference [39]. It is evident, in Figure 9, after adsorption of xanthate; that some peaks appear around $1110 \mathrm{~cm}^{-1}$ and $1045 \mathrm{~cm}^{-1}$, which differ some wave numbers from that of zinc sulfide (Figure 9(a)) and octyl xanthate (Figure $9(\mathrm{~d})$ ), indicating the feature spectra of adsorbed xanthate. It can also be observed that at the zinc rich $\mathrm{ZnS}$ surface the IR spectrum red shifts more than that of stoichiometric ZnS. In Figure 9, there are

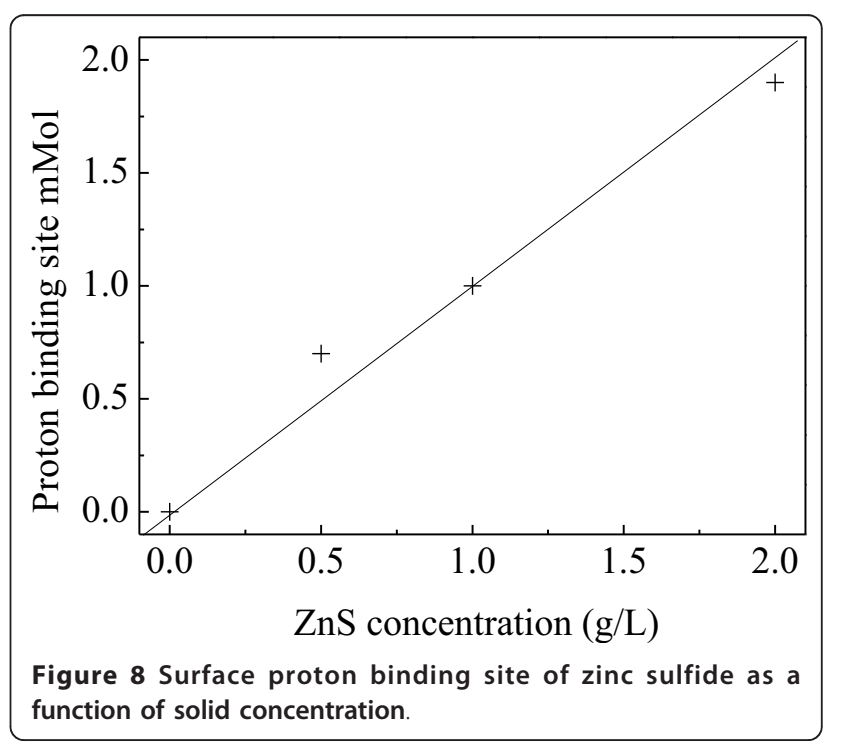




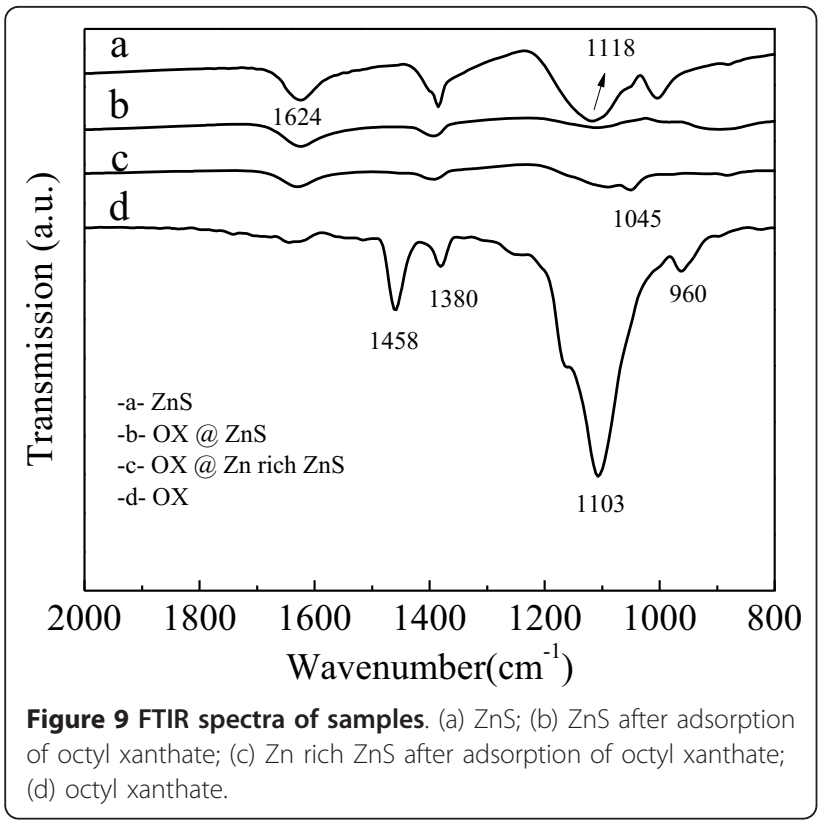

also distinct bands originating from the aliphatic chain of the xanthate molecule, such as bands with peak frequencies around $1388 \mathrm{~cm}^{-1}\left(\delta_{\mathrm{s}}\left(\mathrm{CH}_{3}\right)\right)$.

As a model substance of sulfide minerals the xanthate adsorption mechanism at zinc sulfide may give information about adsorption mechanism at the other sulfide mineral surfaces as well. Figure 10 shows the adsorption behaviors of ethyl and octyl xanthate at zinc sulfide surfaces as a function of $\mathrm{pH}$. The adsorption of xanthate decreased with increasing solution $\mathrm{pH}$ from $\mathrm{pH} 8$ to $\mathrm{pH}$ 11 , indicating a $\mathrm{pH}$ dependent adsorption behavior of xanthate at zinc sulfide and ion exchange between the adsorbed xanthate and hydroxide ions in solution. This phenomenon was reported as the well known Barsky

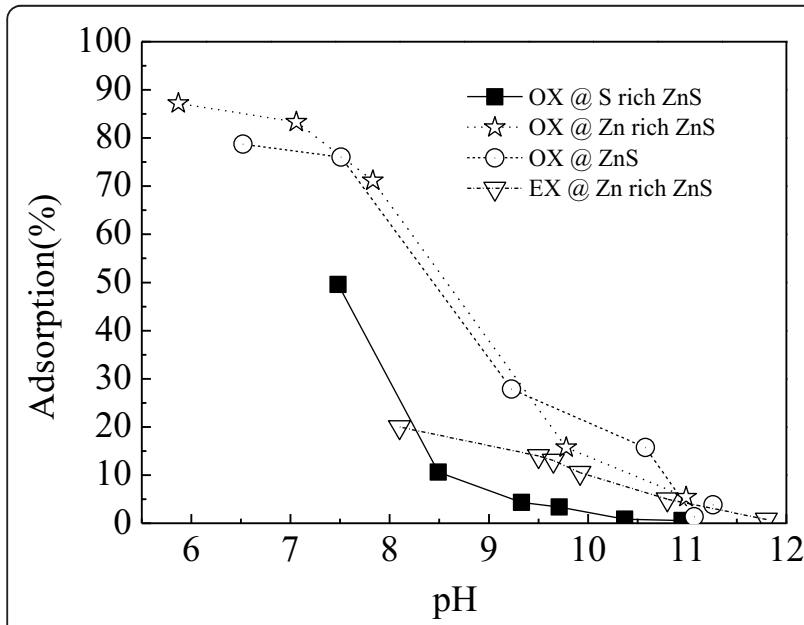

Figure 10 Adsorption of ethyl and octyl xanthate at the surface of zinc sulfide as a function of solution $\mathrm{pH}$. relation [40], i.e. the ratio between free xanthate and free hydroxide in solution is constant, which was derived from the critical $\mathrm{pH}$ value of collector adsorption. Bearing in mind the surface protonation phenomena reported in this study, the Barsky relation should also be closely related with the surface pKa values of the sulfide minerals. It is also noticed that the adsorption quantity of octyl xanthate at the surface of sulfur rich surface is less than that of zinc rich and stoichiometric zinc sulfide. It is also evident that the ethyl xanthate is adsorbed less than that of octyl xanthate at the same $\mathrm{pH}$ region.

\section{Zeta potential measurements}

In order to further investigate the reasons, some zeta potential measurements were carried out; the results are presented in Figure 11. It can been seen from Figure 11 that the sulfur rich $\mathrm{ZnS}$ sample has more negative zeta potential, which can explain why it can adsorb less xanthate i.e. the more negative surface charge prevent xanthate from adsorption. In comparison to xanthate ions, sulfide may be more competitive ions for surface zinc site, because the solubility product of $\mathrm{ZnS}$ is much less than that of zinc xanthate. From Figure 11 we can also see that the zinc rich $\mathrm{ZnS}$ sample has slightly less negative zeta potential than that of the stoichiometric $\mathrm{ZnS}$, which can explain why it can adsorb more xanthate than the others. It is not surprising that the surface electro kinetic properties of zinc rich $\mathrm{ZnS}$ is similar to that of the stoichiometric $\mathrm{ZnS}$, some surface excess zinc ions may be released from the surfaces during hydration especially in alkaline $\mathrm{pH}$, in which zinc hydroxide will be formed. It is worth to note that the $\mathrm{pHpzc}$ of the sample are all near $\mathrm{pH}=2.5$, indicating at acidic $\mathrm{pH}$ the surface are similar, i.e. the excess zinc ions or sulfide ions may be released from the surfaces. From the solution speciation in Figure 2, we can

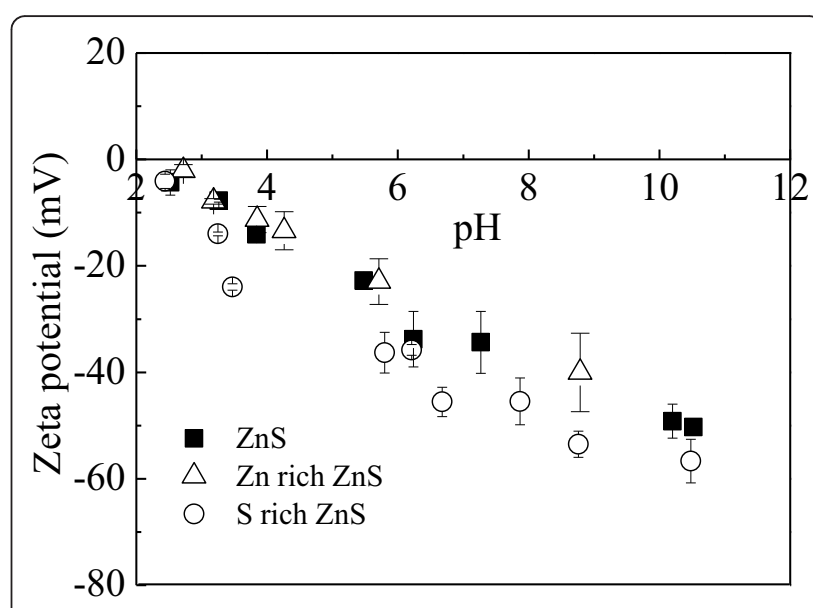

Figure 11 Zeta potential of different zinc sulfide samples as a function of $\mathrm{pH}$. 
understand that in acidic $\mathrm{pH}$, the zinc ions may transfer from the surfaces into solution in the suspension of zinc rich samples and sulfide ions may transfer from the surfaces into solution by forming $\mathrm{H}_{2} \mathrm{~S}$ in the suspension of sulfide rich samples.

In the process of inorganic synthesis of nanoparticles, employing template such as xanthate [31-33] may be needed in order to obtain ideal products. The interaction of template with solid surface and transformation of precursor into metal sulfide nanoparticles are necessary steps. The surface stoichiometry and sorption properties of zinc sulfide shall directly influence the quality of final nanoparticle products, which dictates the releasing rate of metal ions from metal xanthate precursors. Therefore the studies of the surface fundamental properties will help to understand relevant process regarding inorganic synthesis and to elucidate the mechanisms so as to optimize the synthesis process.

\section{Experimental \\ Chemicals}

Zinc nitrate, sodium sulfide, sodium hydroxide, potassium hydroxide, hydrochloric acid, sodium nitrate, carbon disulfide, acetone, petroleum ether, ethanol, octanol and ethyl xanthate are all analytical grades and were purchased from Sinopharm Chemical Reagent Co., Ltd. Octyl xanthate were synthesized using carbon disulfide, octanol and potassium hydroxide as source materials and recrystallized three times using acetone and petroleum ether to get enough purity (>99\%). Doubly distilled water was used throughout entire study.

\section{Sample preparation}

Stoichiometric zinc sulfide sample was prepared by precipitation from a stoichiometric mixture of aqueous zinc nitrate and sodium sulfide and the specific surface area of this sample was determined by Nova 2000e BET instrument from Quantachrome to be $37.6 \mathrm{~m}^{2} / \mathrm{g}$. The zinc rich zinc sulfide sample was prepared by precipitation from a nonstoichiometric mixture of 2 parts of aqueous zinc nitrate $(0.2 \mathrm{M})$ and 1 part of sodium sulfide $(0.1 \mathrm{M})$. The sulfide rich zinc sulfide sample was prepared by precipitation from a nonstoichiometric mixture of 2 parts of sodium sulfide $(0.2 \mathrm{M})$ and 1 part of aqueous zinc nitrate $(0.1 \mathrm{M})$. The BET surface for sulfide rich and zinc rich samples are considered to be about the same as that of the stoichiometric sample because both the synthesis process and the mass of solid formed are basically the same. All samples were rinsed with doubly distilled water three times and dried in an oven at $80^{\circ} \mathrm{C}$ for over 8 hours.

\section{Sample surface characterization}

Fourier transforms infrared (FT-IR) measurements samples in $\mathrm{KBr}$ pellets were carried out by means of a
Bruker Vertex 70 FT-IR spectrometer. One centimetre diameter and constant weight $\mathrm{KBr}$ pellets were prepared by mixing the sample with $\mathrm{KBr}$ at 1:100 ratios. The spectra were measured in the wavenumber range of $400-4000 \mathrm{~cm}^{-1}$ with 100 scans at $4 \mathrm{~cm}^{-1}$ resolution.

Zeta potential of samples was measured using a Zeta meter (JS94H) based on the mobility of electrophoresis. The zeta potential measurements of sample as a function of $\mathrm{pH}$ were carried out in the solution with the ionic strength of $1 \mathrm{mM} \mathrm{NaNO}$. In this procedure, a series of sample in a closed $50 \mathrm{~mL}$ polyethylene test tube with solid sample concentration of $0.8 \mathrm{~g} \mathrm{~L}^{-1}$ was conditioned in a thermostatic shaker at $25^{\circ} \mathrm{C}$. The $\mathrm{pHs}$ of the suspensions were adjusted using either acid (0.1 $\mathrm{M} \mathrm{HCl})$ or base $(0.1 \mathrm{M} \mathrm{NaOH})$ solutions. After shaking overnight $(24 \mathrm{~h})$, the samples were allowed to stand for 5 min to let larger particles settle. An aliquot taken from the supernatant was used to measure the zeta potentials. The average of 5 measurements was taken to represent each measured potential and the error range of the measurements is also marked in the presented diagram.

\section{Potentiometric titration}

The sulfide samples of different solid weight $(0.05 \mathrm{~g}$, $0.10 \mathrm{~g}$ and $0.20 \mathrm{~g}$ ) in a titration vessel with $100 \mathrm{~mL} 0.1$ $\mathrm{M} \mathrm{NaNO}_{3}$ solution (with a stop and without special protection from an inert gas) were titrated respectively with acid $(0.1133 \mathrm{M} \mathrm{HCl})$ or base solution $(0.10 \mathrm{M}$ $\mathrm{NaOH}$ ), and after conditioned magnetically for $5 \mathrm{~min}-$ utes, the resulting $\mathrm{pH}$ was recorded. The glass electrode was calibrated using the standard $\mathrm{pH}$ buffer solutions before each titration.

\section{Adsorption}

The adsorption studies of ethyl and octyl xanthate by various $\mathrm{ZnS}$ samples $(0.8 \mathrm{~g} / \mathrm{L})$ were conducted by a batch technique at $25^{\circ} \mathrm{C}$. For these adsorption studies, a series of $50 \mathrm{~mL}$ polyethylene test tube containing $25 \mathrm{~mL}$ of xanthate solutions of $0.05 \mathrm{mM}$ concentrations closed with a stop were employed at a varying $\mathrm{pH}$. All $\mathrm{pH}$ adjustments were made by adding the requisite amount of dilute acid $(\mathrm{HCl})$ and dilute base $(\mathrm{NaOH})$ and the influence of $\mathrm{pH}$ was then determined by examining the adsorption of xanthate at a desired concentration over a $\mathrm{pH}$ range of 5.0-12.0. These in a thermostatic shaker were shaking continuously for 60 minutes to attain equilibration and then a part of the suspension was withdrawn and centrifuged at $16000 \mathrm{rpm}$ for 10 minutes. The residual concentration of xanthate in the supernatant was then determined spectrophotometrically by measuring the absorbance at $\lambda_{\max }$ of $301 \mathrm{~nm}$ against the standard calibration curve with linearity of $R^{2}=0.9991$ between 0.0 and $0.1 \mathrm{mM}$. The $\mathrm{pH}$ value of the $\mathrm{ZnS}$ 
suspension before centrifugation was recorded using a combined glass electrode, which was calibrated using standard $\mathrm{pH}$ buffer solutions before use.

\section{Speciation modeling}

The speciation modeling of solution species was carried out using computer program MEDUSA and the relevant equilibrium constants were collected from the MEDUSA database [35]. In performing the speciation modeling, we need assigning the concentration for each involved component and selecting the diagram type before running MEDUSA program to get calculation results and relevant diagrams. For example, to get the predominant $\mathrm{E}_{\mathrm{h}}-\mathrm{pH}$ diagram in $\mathrm{Zn}^{2+}-\mathrm{HS}^{-}-\mathrm{e}^{-}-\mathrm{H}_{2} \mathrm{O}$ system, we need giving the concentration for $\mathrm{Zn}^{2+}$ and $\mathrm{HS}^{-}$, the $\mathrm{E}_{\mathrm{h}}$ and $\mathrm{pH}$ range before running MEDUSA. The calculations cover all possible chemical reactions in $\mathrm{Zn}^{2+}-\mathrm{HS}^{-}-\mathrm{e}^{-}-$ $\mathrm{H}_{2} \mathrm{O}$ system, including acid-base reactions, redox reactions and precipitation and dissolution reactions presented in Table 1.

\section{Conclusions}

In the present work we have evaluated the surface properties of stoichiometric, zinc rich and sulfur rich synthetic zinc sulfide nanoparticles by acid base potentiometric titration in combination with UV-Visible spectroscopic measurements for xanthate adsorption. Following conclusions can be drawn from our studies:

1. Potentiometric titration is a useful tool in the determination of surface proton binding site of zinc sulfide and in the evaluation of surface stoichiometry. The surface proton binding site determined was found to be increased quantitatively with increasing solid concentration of zinc sulfide.

2. The surface stoichiometry strongly affects the surface properties of zinc sulfide; either zinc rich or sulfur rich surface will bring different acid base properties, i.e. different surface acidity constants.

3. Xanthate adsorption at the surface of zinc sulfide decreased with decreasing surface zinc ions and increasing solution $\mathrm{pH}$ indicating the importance of surface zinc site and an ion exchange process between the hydroxide ions in mineral suspension and adsorbed xanthate ions at the surfaces.

\section{Acknowledgements \\ Financial support from Chinese Natural Science Foundation (No.50874052; No. 20677022) and National Basic Research Program of China (No. 2011CB933700) is gratefully acknowledged.}

\section{Authors' contributions}

MW carried out most experiments and drafted the manuscript; QZ carried out the measurement of acid base titration; WH assisted to the equilibrium calculations; ZS has formulated the research idea and finalized the manuscript. All authors have read and approved the final version.

\section{Competing interests}

The authors declare that they have no competing interests.

Received: 6 July 2011 Accepted: 24 November 2011

Published: 24 November 2011

\section{References}

1. Bhargava RN, Gallagher D: Optical properties of manganese-doped nanocrystals of ZnS. Phys Rev Lett 1994, 72:416-422.

2. Bhargava RN: Doped nanocrystalline materials - Physics and applications. J Lumin 1996, 70:85-94

3. Yu I, Isobe T, Senna M: Optical properties and characteristics of ZnS nanoparticles with homogeneous Mn distribution. J Phys Chem Solids 1996, 57:373-379.

4. Sooklal K, Cullum BS, Angel SM, Murphy CJ: Photophysical properties of ZnS nanoclusters with spatially localized $\mathrm{Mn}^{2+}$. J Phys Chem B 1996, 100:4551-4555.

5. Huang J, Yang Y, Xue S, Yang B, Liu S, Shen J: Photoluminescence and electroluminescence of $\mathrm{ZnS}$ : Cu nanocrystals in polymeric networks. App/ Phys Lett 1997, 70:2335-2337.

6. Chamarro MA, Voliotis V, Grousson R, Lavallard P, Gacoin T, Counio G, Boilot JP, Cases R: Optical properties of Mn-doped CdS nanocrystals. J Crystal Growth 1996, 159:853-856.

7. Soo YL, Ming ZH, Huang SW, Kao YH, Bhargava RN, Gallagher D: Local structures around $\mathrm{Mn}$ luminescent centers in Mn-doped nanocrystals of ZnS. Phys Rev B 1994, 50:7602-7607.

8. Ito H, Takano T, Kuroda T, Minami F, Akinaga H: Two-dimensional confinement effect on $\mathrm{Mn}^{2+}$ intraionic transition. J Lumin 1997, 7274:342-343.

9. Yu J, Liu H, Wang Y, Fernandez FE, Jia W, Sun L, Jin C, Li D, Liu J, Huang S: Irradiation-induced luminescence enhancement effect of $\mathrm{ZnS}: \mathrm{Mn}^{2+}$ nanoparticles in polymer films. Opt Lett 1997, 22:913-915.

10. Bol AA, Meijerink A: Doped semiconductor nanoparticles - a new class of luminescent materials. J Lumin 2000, 87-89:315-318.

11. Zhao Q, Xie Y, Zhang Z, Bai X: Size-selective synthesis of zinc sulfide hierarchical structures and their photocatalytic activity. Cryst Growth Des 2007, 7:153-158.

12. Li Y, Zou K, Shan Y, Zapien JA, Lee ST: Catalyst-assisted formation of nanocantilever arrays on ZnS nanoribbons by post-annealing treatment. J Phys Chem B 2006, 110:6759-6762.

13. Moore D, Ding Y, Wang ZL: Hierarchical structured nanohelices of ZnS. Angew Chem Int Ed 2006, 45:5150-5154.

14. Zhang Y, Lu F, Wang Z, Wang H, Kong M, Zhu X, Zhang L: ZnS nanoparticle-assisted synthesis and optical properties of $\mathrm{ZnS}$ nanotowers. Cryst Growth Des 2007, 7:1459-1462.

15. Wolosiuk A, Armagan O, Braun PV: Double direct templating of periodically nanostructured ZnS hollow microspheres. J Am Chem Soc 2005, 127:16356-16357.

16. Son D, Wolosiuk A, Braun PV: Double direct templated hollow ZnS microspheres formed on chemically modified silica colloids. Chem Mater 2009, 21:628-634.

17. Yao W, Yu S, Wu Q: From mesostructured wurtzite ZnS - nanowire/amine nanocomposites to $\mathrm{ZnS}$ nanowires exhibiting quantum size effects: a mild-solution chemistry approach. Advanced Functional Materials 2007, 17:623-631.

18. Muruganandham M, Amutha R, Repo E, Sillanpää M, Kusumoto Y, AbdullaAl-Mamun MD: Controlled mesoporous self-assembly of ZnS microsphere for photocatalytic degradation of Methyl Orange dye. J Photochem Photobiol, A: Chem 2010, 216:133-141.

19. Gough DV, Wolosiuk A, Braun PV: Mesoporous ZnS nanorattles: programmed size selected access to encapsulated enzymes. Nano Letters 2009, 9:1994-1998.

20. Sun ZX, Zhang Q, Lu YH, Li YL: Synthesis of mesoporous ZnS nanoparticles with enlargeable pore size through a co-template approach. Microporous and Mesoporous Materials 2008, 109:376-382.

21. Zhang WM, Li HM, Sun ZX, Zhang Q, Forsling W: Synthesis of mesoporous ZnS synergistically templated by butylamine and alkanols. Microporous \& Mesoporous Materials 2012, 147:222-228.

22. Zhang HZ, Gilbert B, Huang F, Banfield JF: Water-driven structure transformation in nanoparticles at room temperature. Nature 2003, 424:1025-1029. 
23. Gilbert B, Huang F, Zhang H, Waychunas GA, Banfield JF: Nanoparticles: strained and stiff. Science 2004, 305:651-654

24. Rönngren L, Sjöberg S, Sun ZX, Forsling W, Schindler PW: Surface reactions in aqueous metal sulfide systems, 2 . lon exchange and acid/base reactions at the $\mathrm{ZnS}-\mathrm{H}_{2} \mathrm{O}$ interface. J Colloid and Interface Science 1991 145:396-404.

25. Rönngren L, Sjöberg S, Sun ZX, Forsling W: Surface reactions in aqueous metal sulfide systems, 5 . The complexation of sulphide at $\mathrm{ZnS}-\mathrm{H}_{2} \mathrm{O}$ and PbS- $\mathrm{H}_{2} \mathrm{O}$ interface. J Colloid and Interface Science 1994, 162:227-235.

26. Sun ZX, Forsling W, Rönngren L, Sjöberg S: Surface reactions in aqueous metal sulfide systems, 1. Fundamental surface properties of hydrous $\mathrm{PbS}$ and ZnS. Inter J Min Proc 1991, 33:83-93.

27. Gärd R, Sun ZX, Forsling W: FT-IR and FT-Raman studies of colloidal ZnS, 1. Identity of S-H and $\mathrm{Zn}-\mathrm{OH}$ bonds at the $\mathrm{ZnS} /$ water interface. J Colloid and Interface Science 1995, 169:393-399.

28. Sawant P, Kovalev E, Klug JT, Efrima S: Alkyl xanthates: new capping agents for metal colloids. Capping of platinum nanoparticles. Langmuir 2001, 17:2913-2917.

29. Tzhayik O, Sawant P, Efrima S, Kovalev E, Klug JT: Xanthate capping of silver, copper, and gold colloids. Langmuir 2002, 18:3364-3369.

30. Nair P, Radhakrishnan T, Revaprasadu N, Kolawole G, O'Brien P: Cadmium ethylxanthate: A novel single-source precursor for the preparation of CdS nanoparticles. J Mater Chem 2002, 12:2722-2725.

31. Pradhan N, Efrima S: Single-precursor, one-pot versatile synthesis under near ambient conditions of tunable, single and dual band fluorescing metal sulfide nanoparticles. J Am Chem Soc 2003, 125:2050-2051.

32. Pradhan N, Katz B, Efrima S: Synthesis of high-quality metal sulfide nanoparticles from alkyl xanthate single precursors in alkylamine solvents. J Phys Chem B 2003, 107:13843-13854.

33. Zhang WM, Sun ZX, Hao W, Su DW, Vaughan D: Synthesis of size tuneable cadmium sulphide nanoparticles from a single source precursor using ammonia as the solvent. Material Research Bulletin 2011, 46:2266-2270.

34. Brown GE, Henrich VE, Casey WH, Clark DL, Eggleston C, Felmy A, Goodman DW, Gratzel M, Maciel G, McCarthy Ml, Nealson KH, Sverjensky DA, Toney MF, Zachara JM: Metal oxide surfaces and their interactions with aqueous solutions and microbial organisms. Chem Rev 1999, 99:77-174

35. Puigdomenech I: MEDUSA Chemical Equilibrium Software, Royal Institute of Technology, Sweden. 1999, Updated 18-Feb.-2004.

36. Gran G: Determination of the equivalence point in potentiometric titrations. The Analyst 1952, 77:661-671.

37. Fredriksson A, Holmgren A: An in situ ATR-FTIR investigation of adsorption and orientation of heptyl xanthate at the lead sulphide/ aqueous solution interface. Minerals Engineering 2008, 21:1000-1004.

38. Fredriksson A, Hellstrom P, Oberg S, Holmgren A: Comparison between in situ total internal reflection vibrational spectroscopy of an adsorbed collector and spectra calculated by ab initio density functional theory methods. Journal of Physical Chemistry C 2007, 111:9299-9304.

39. Colthup NB, Powel LP: Vibrational analysis of alkyl xanthates. Spectrochimica Acta 1987, 43A:317-322.

40. Barsky G: Discussion of paper by Wark and Cox (Foot-note No.3). Trans AIME 1934, 112:236-237.

doi:10.1186/1752-153X-5-73

Cite this article as: Wang et al:: Surface stoichiometry of zinc sulfide and its effect on the adsorption behaviors of xanthate. Chemistry Central Journal 2011 5:73.

\section{Publish with ChemistryCentral and every scientist can read your work free of charge \\ "Open access provides opportunities to our colleagues in other parts of the globe, by allowing anyone to view the content free of charge."}

W. Jeffery Hurst, The Hershey Company.

- available free of charge to the entire scientific community

- peer reviewed and published immediately upon acceptance

- cited in PubMed and archived on PubMed Central

- yours - you keep the copyright

Submit your manuscript here:

http://www.chemistrycentral.com/manuscript/<smiles>c1ccccc1</smiles> 